processes active within a sportsperson in terms of his cognitive, affective and conative ability that results in enhancing his confidence, attention span and composure to perform optimally in adverse situations.

\title{
180 PSYCHOLOGY BEHIND OPTIMAL PERFORMANCE
}

Gurpreet Kaur, R R Kotwal, Soumi Awasthy Defence Institute of Psychological Research, DRDO, Delhi, India

\subsection{6/bjsm.2010.078725.180}

Human behaviour is studied across a wide range of people from the emotionally disturbed to the healthy. Study of human behaviour helps to break through the mental barriers, facilitating the performance and enhancing consistency of performance. Psychology has traditionally been identified and studied as a trilogy of the mind: cognition, affect and conation. Cognition refers to concentration, attention, alertness, focus and other mental attributes. Affect includes anxiety, fear and stress proneness. Conation refers to the striving component (the mental processes) which causes an individual to act, react and interact according to an innate pattern of behaviour. It includes the psychomotor abilities which characterise mental processes that have motor consequences. Conation thus includes psychomotor abilities and motivation of the individual, which can be either intrinsic or extrinsic. These three domains viz. cognition, affect and conation affect an individuals performance. For example a small event, even a minor injury, on the match day can make a sportsperson doubt his ability. Thus affecting his concentration (cognition), by causing anxiety (affect) enhancing/degrading his reaction time to perform (conation). Under undue stressful conditions sportspersons tend to have a narrow attention span, often referred to as 'Tunnel Vision'. Attention may also focus on the athlete's internal thought process which can lead to 'choking' under pressure. The present paper is an approach to help understand the effective latent 